\title{
Afterword: Evidence over Interests
}

\author{
John P. Gluck \\ Professor Emeritus, University of New Mexico; Research Professor, Kennedy \\ Institute of Ethics, Georgetown University, United States \\ jgluck@unm.edu
}

After years of science education, teaching experience, and research practice, which focused on the use of non-human primates as potential models of human psychological disorders, a young student in my primate behavior class amiably, but insistently, suggested my preparation was incomplete. She asked me to read Peter Singer's book Animal Liberation, which had been published two years earlier, in 1975. I had been lecturing in class about the effects of early experience on the rhesus monkey's (Macaca mulatta) social and intellectual development, and my descriptions of the invasive research interventions and behavioral consequences encouraged her to make the book suggestion. I said I would try to find the time, but that I was busy. She handed me a fresh new copy of the book saying, "This is for you." She made it clear that she was not loaning me her copy but wanted the book to be part of my professional library. Over the following weeks while describing this event to colleagues, many also involved in animal research, I asked them if they had read Professor Singer's book. While some had heard of it, no one had actually read it. "Why should I do that?" was a common tone of the comments. After all, our experimental standards were quite clear and seemed self-evidently valid. That is, if any interesting and, therefore, valuable research question could not be tested in humans for ethical reasons, then it could be evaluated in animal models. Progress required risk, and progress was urgently needed. This powerful drive to know and understand nature, so as to improve the welfare of human beings, was what the bioethicist Paul Ramsey (1976) called, the research imperative, to emphasize its motivational dominance.

In response to the student's questioning looks as we saw one another in class, and out of respect for her serious intention, I did finally read Animal Liberation. The chapter titled, Tools for research or what the public doesn't know it is paying for, quickly trapped my attention. Three of the assertions of the chapter were: (1) The raw descriptions of the experimental manipulations done to animals revealed a shocking emotional callousness on the part of investigators; (2) The extent of the harms, which the animals were required to absorb, seemed excessive in comparison with the many obvious or even trivial facts discovered; (3) It was estimated that after all the experimental effort and

(C) JOHN P. GLUCK, 2019 | DOI:10.1163/9789004391192_030

This is an open access chapter distributed under the terms of the prevailing CC-BY-NChLicense at the time 9004391192 of publication. 
animal suffering, approximately one quarter of the studies actually made it into the open scientific literature. I thought the number was significantly less than $25 \%$. More personally, a significant part of the chapter raised specific ethical questions about the research of Harry F. Harlow, which also involved studying the effects of socially isolating infant rhesus monkeys from their mothers and peers. Harlow was once one of my central mentors in graduate school and continued to support me by providing monkey subjects and experimental advice. Singer described the laboratory where I was educated, and he sounded morally disgusted. While I mostly rejected the implication, it was clear that the basic assertion of Animal Liberation was that our vague and rarely articulated ethical assumptions, when placed under the light of a sophisticated utilitarian ethical analysis, revealed themselves to be simplistic, self-serving, and mostly indifferent to science-generated animal harm and suffering.

As my colleagues and I began to see an increase in the number of pointed questions about the validity and justification of animal models from students, a few scientists, and from the public after 1975, curiosity about the controversy and the issues raised turned to hardened defensiveness and something approaching contempt for the questioners. We bolstered our dismissiveness by making forceful statements about the demands of the research imperative and the extent of human clinical need. We remained blind or just mute about the dangers that can accrue when an imperative becomes an omnipotent and unassailable directive.

More subtle, but perhaps more dangerous, is that there is evidence that many researchers have neglected and continue to neglect the notion that science is not just based on acts of direct perception of nature, followed by the straightforward description of facts. Rather, it is a process strongly influenced by psychological, social, and cultural forces. Ludwik Fleck, a microbiologist who wrote as early as 1935 about how different sides of many scientific controversies evolved into thought collectives that demanded loyalty to the beliefs of the collective and disdain for outsiders. Fleck showed that the collectives were capable of shaping thought styles that could have the effect of limiting the ability of members to actually understand divergent perspectives and to take alternative research paths. The magisterial work of Thomas Kuhn (1962), in The Structure of Scientific Revolutions, which built on Fleck (1935), articulated how, what he termed, "normal science" could actively deny incorporating experimental findings that had the potential to disconfirm entrenched methods and explanations. More recently, historians of science, such as David Wootton (2007) in his book Bad Medicine: Doctors Doing Harm since Hippocrates, further elaborate how the tendency of scientists to confer authority to "established" theories and methods have been the central factor in the delay of medical progress, and so it is now with much of the work in animal research. 
Animal Experimentation: Working Towards a Paradigm Change illustrates how these crucial cautions about doing science, and the necessity to understand the complex nature of methodological choices, have remained surprisingly weak in encouraging checks on the tribal-like loyalty to the continued use of animal models in the face of contrary evidence. It is as if Claude Bernard's (the father of modern physiology) brash nineteenth century assurance that "experiments on animals are entirely conclusive for the toxicology and hygiene of man" (Hajar, 2011) is in no need of modification. This trust is maintained even in the face of the moral demands left by our increased knowledge of the cognitive and emotional capabilities of the "other", and the scientific understanding of physiological processes taking place below the level of magnification of the common microscope. By the time you, the readers, are at this point in this volume, you have been exposed to an incredible variety of evidence of the empirical failure of animal models to protect humans and to control many diseases and maladies. You have seen the existence of regulatory dysfunction, along with good faith attempts to structure legal systems that confront outmoded, ineffective, and pain-provoking research traditions. You have had a look at parts of the incentive structure of science and its unfortunate facilitation of the good soldier keeping in line with traditional, safe expectations in order to produce long vitas that are likely to be short on breakthroughs and revolutionary excursions.

This carefully constructed and edited book needs to be held close by those with brave-thinking hearts. I will place my copy right next to my well-worn edition of Animal Liberation given to me many years ago.

\section{References}

Fleck, L. (1935). Genesis and development of a scientific fact. Chicago, IL: University of Chicago Press.

Hajar, R. (2011). Animal Testing and Medicine. Heart Views: The Official Journal of the Gulf Heart Association, 12(1), p. 42.

Kuhn, T. (1962). The structure of scientific revolutions. Chicago, IL: University of Chicago Press.

Ramsey, P. (1976). The Enforcement of Morals: Nontherapeutic Research on Children. Hastings Center Report, 6(4), p. 2.

Singer, P. (1975). Animal liberation. New York: Avon Books.

Wootton, D. (2007). Bad medicine: Doctors doing harm since Hippocrates. Oxford, UK: Oxford University Press. 